DOI https://doi.org/10.18551/rjoas.2017-06.19

\title{
THE ANTECEDENTS OF DEVIANT WORKPLACE BEHAVIORS ON THE EMPLOYEES OF REGIONAL APPARATUS ORGANIZATION (ODP) IN MALUKU PROVINCE, INDONESIA
}

\author{
Leweherilla Novalien C. \\ University of Pattimura, Indonesia \\ E-mail: novalewaherilla@yahoo.com
}

\begin{abstract}
The phenomenon of deviant workplace behavior has become increasingly interesting to be examined. Many studies have much more seen this by focusing on the employees of private sectors rather than on those of public sectors. This study believes that it is seriously important to examine the factors influencing deviant behaviors for the employees of Regional Apparatus Organization (OPD) in Maluku Province. The emerging phenomenon was that deviant behavior, either internal or organizational deviance, mostly occurred among the employees. Hence, this study tried to analyze the variables of ethical climate, national culture, workplace spirituality, along with the organizational commitment and its effect on deviant behavior, either directly or indirectly.
\end{abstract}

\section{KEY WORDS}

Ethical climate, national culture, workplace spirituality, organizational commitment, deviant behavior.

Regional Apparatus Organization (OPD) is a state apparatus, which has an important role in servicing public or society. As the public demands for service quality continue to grow, the function of regional apparatus as a public servant is to fulfill the needs of the service recipients or to conduct the legislative provision.

The employees of regional apparatus, either in the level of province or city/regency, should commit public service as mentioned in Law No.5 of 2014 - that Civil State Apparatus $(A S N)$ is a profession based on principles such as being committed, having moral integrity and being responsible for the public. However, the fact often suggests that civil servants conduct less-committed attitude on the works and organizations. The low commitment may become the reason of the existing deviant workplace behavior. According to Dalal (2005) or Spector \& Fox (2002), an employee who has a strong commitment to an organization tends to have a relatively small negative attitude.

One of the regions in Indonesia, which continuously try to increase public service quality, is Maluku Province. In general, there are 11 regencies/cities located in the region of Maluku Province. In the government implementation/administration, the phenomenon of deviant workplace behavior is also often found in the Regional Apparatus Organizations (OPD) which exist either on the level of regency/city or province of Maluku. Based on the result of the survey, it was found that the violation trends were mostly still carried out by the employees. It covered from the small ones such as being late to work, going home earlier or entering without permission, working not maximally, playing truant and relaxing out during office hours, until the big ones including sexual deviance cases and organizational harming behaviors such as the use of state funds due to a consumptive lifestyle, authority abusing, even manipulation and corruption that were mostly done by the government employees or officials. This has greatly influenced the performance of public service. Those deviant behaviors also have resulted in economic losses and hampered the effort of improved public service.

The awareness as Civil State Apparatus (ASN) that has not been completely owned was influenced by either internal or external organizational factor. The work attitude in relation to public service was incompatible with the ethical standards of PNS (civil servants) and the applicable rules or law of employment. It led to the occurrences of deviance 
practices in the workplace. As mentioned in the $8^{\text {th }}, 9^{\text {th }}$, and $10^{\text {th }}$ articles of Government Regulation No.42 of 2004 that the code of ethics of civil servants must be accountable in carrying out the function of administering a government that is clean, authoritative, responsive, open, honest, accurate, and always on time in conducting all government policies and programs, using or utilizing all the state resources efficiently and effectively.

Deviant behavior (workplace deviance) is defined as a behavior carried out intentionally and in opposition to the applicable norms in an organization that can threaten the organizational or member sustainability, even both of the two (Bennett \& Robinson, 2000). Deviant behaviors give negative impact on the organizational sustainability. In the context of government organizations, deviant behaviors can trigger the emergence of public mistrust, economic resources losses, and failure in achieving development purpose that has been determined by the government and even affect the PDB (Gross Domestic Product) or manpower. Deviant workplace behaviors are also closely related to the norms and values believed in an organizational culture. Cultures become an important thing that needs to be implemented by an organization to overcome the problems of deviant workplace behaviors (Appelbaum, 2005). Those norms not only include the company policy that bans specific behaviors such as stealing, but also constitute unwritten rules (Robbin,2008:39). The implementation of cultural values (either organizational or national culture) on the employees of regional apparatus that has not been maximum could influence the employees' work attitudes. Cultures become a norm that should be followed although the tendency to bring a personal culture is still attributed to an employee. Additionally, the values of workplace spirituality have not fully become a real part of employees.

If internal problems of an organization including ethical climate, national culture, and workplace spirituality cannot be settled well, deviant behaviors then may occur. This is because the employees lose their commitment to the organization they work in. The civil servants who commit to their organization can be seen from their work behaviors and attitudes. Their big intention or willingness to serve the organization has made them uphold the values of being an employee. Furthermore, an attitude of unconditional loyalty will be the characteristic of employees who make commitments. The employees will also have high work ethos to make a performance through work quality, quantity, and punctuality.

By grounding to the background above, the statements of problems of this study are:

- Does ethical climate influence deviant behavior?

- Does ethical climate influence workplace spirituality?

- Does workplace spirituality influence deviant behavior?

- Does workplace spirituality mediate the influence of ethical climate on deviant behavior?

- Does national culture influence deviant behavior?

- Does national culture influence workplace spirituality?

- Does workplace spirituality mediate the influence of national culture on deviant behavior?

- Does ethical climate influence organizational commitment?

- Does organizational commitment influence deviant behavior?

- Does organizational commitment mediate the influence of ethical climate on deviant behavior?

- Does national culture influence organizational commitment?

- Does organizational commitment mediate the influence of national culture on deviant behavior?

- Does workplace spirituality influence organizational commitment?

\section{THEORETICAL REVIEW}

Deviant Behavior. Robinson and Bennet (1997) explained that there are 3 different trend areas of study in examining deviant behavior. The first area includes the studies in which deviant behavior is conceptualized as a reaction to the experience in workplace. The 
second area refers to the studies that examine deviant behavior as the reflection of employees' personalities, while the third area includes the studies that predict the combination between individual character and organizational situation. Bruursema (2004) and Mount et al. (2006) stated that the studies on deviant behaviors were mostly learned in various perceptions, ones of which were outcome variable and predictor variable. There are some terms often used in any kinds of literature to define a deviant behavior such as counterproductive behavior, antisocial behavior, misconduct, or workplace incivility (Caroline, 2015). Although it has been mentioned in different perspectives, the definitions of deviant behavior are relative the same. Robinson \& Bennet (1997) defined a deviant behavior as a behavior that is intentionally and consciously conducted in contrast with the norms ruled by an organization and it threatens the condition of the organization and the other members. Fieldman (1984) added that what the organizational norms mean is consisted of basic moral standards and the traditional standards of other communities, including formal and informal written policies, rules, and procedures of other organizers. Another definition was also revealed by Vardi \& Weiner (1996), saying that a deviant workplace behavior refers to a behavior resulting in the emergence of danger or having a possibility to endanger the social norms that have been precisely designed. The behaviors are aimed at individual and organization.

Although defined differently, the behaviors lead to negative impacts for individual or organization performance in general (Judge \& Scott, 1995; Maufi, 2011) as well as trigger members' intention to exit, members' satisfaction, a decreased organizational power, stealing, etc. (Bollin \& Heatherly, 2001). Furthermore, Zribi \& Souai (2013) explained that there are 3 essential principles that can be used to characterize deviant behaviors. First, deviant behaviors systematically bring destructive impacts to an organization. Second, the behaviors must be conducted consciously and not a coincidence. That is, the individuals who behave in distorted ways intentionally oppose the norms that have been determined by an organization. Third, the behaviors are conducted in an organization either directly (sabotage) or indirectly (verbal, physical, moral abuses and sexual disorder). Olabimitan \& Alausa (2014) also stated that there are two ways to distinguish deviant workplace behaviors from any other behaviors, consisting of (1) the volisi, dan (2) the dangerous goals. Thus, accidental deviant behaviors or out-of-control behaviors are not included in the category of deviant workplace behavior. This study would make a further examination regarding the deviant behaviors according to Robinson \& Bennett (1997) in which there are two kinds of deviant behaviors, namely interpersonal deviance, and organizational deviance.

Ethical Climates. The researchers emphasized the importance of studying the ethical climates of the organization because it greatly influences the employees' attitudes and behaviors as well as organization achievement. Schwepker (2001) and Wirawan (2007) defined ethical climate as a perception in organization influencing ethical-contained decisions. This ethical climate then may affect the organization members' behaviors in performing their duties. According to Victor and Cullen (1988), an organizational ethical climate is a perception and an acceptance of individuals on the practices and procedures of an organization. The emerging ethical practices will highly influence the individuals' behaviors and knowledge in reaching good performances. According to fisher and Lovell (2003), the organization management, nowadays, demands an available change in which the traditional becomes modern. The modern not only refers to the use of new technologies but also the involvement of ethical practices (either on the level of managerial or operational) and the practices and procedures in relation to the attitude of an organization to the employees. Appelbaum et al. (2005) then developed the ethical practices in an organization with the statement saying that the ethical climate of organization gives significant contributions to the working relationship and good behavior formation because it includes a set of values and norms that can guide the employees' actions. The organizational ethical climate can encourage the existence of ethical behaviors and conversely may result in the ethical behaviors in the organization. Based on the three ethical criteria above, Victor, Bart and Jhon B. Cullen (1988) hen found that there are five dimensions to measure the organizational ethical climate, which is described in Ethical Climate Questionnaire, namely caring, law and 
code, independence, instrumentalism, and rule. Hence, this study examined the ethical climate based on the dimensions mentioned by Victor and Cullen (1988).

National Cultures. In relation to deviant workplace behaviors, Nasurdin et al. (2014) explained that there are many studies following West tradition. In fact, regional differences will cause varied cultures and influence the organizational behaviors (Rompenaars \& Hampden-Turner, 1993; Trompenaars,1993; and Globe Project, 2003. National or social culture is the highest level of culture and related to socialization. National cultures consist of the values and beliefs that have been obtained since childhood and it continuously develops. Up until now, some different types of the framework (based on the dimensions) are often used in studying national cultures. According to Nazarian et al. (2012), the currently available framework is what has been developed by Kluckhohn \& Strodtbeck (1961), Hall (1976), Hofstede (1983). Hofstede (2011) defined cultures as a mind program that collectively distinguishes the members of a group from other groups, also known as a national cultural concept. The emergence of the concept of a national culture very influences the individuals within a state or an organization. Kirkman et al. (2006) explained that the emergence of various empirical studies regarding the effect of national cultures on the workplace attitudes and behaviors is initiated by the public (Geert Hofstede's study entitled Culture's Consequences: International Differences in Work-Related Values, the 1980s).

This study also examined the issue of national culture in relation to deviant behaviors. Hofstede (2001) has divided the cultural dimension into 4 sections:

1. Individualism (the opposite of collectivism):

Individualism reflects what extent an individual expects personal freedom. This is against collectivism (group) which is defined as the acceptance of responsibility from family, community group (tribe, etc.).

2. Power Distance:

Power distance is defined as a space or distance between the powers of Boss (B) with the Subordinate (S). In the organization hierarchy, the distance refers to the difference between to what extent $B$ can determine the behavior of $S$ and the vice versa.

3. Uncertainty Avoidance:

Future uncertainty is defined as the principle of people's lives. People with a higher future uncertainty level will reduce the impacts of the uncertainty toward technologies, rules, and rituals. Conversely, people with a lower uncertainty avoidance level will be more relaxed so that the practice much more depends on the principle, and their deviation can be more tolerated.

4. Masculinity (the opposite of femininity):

Masculinity emphasizes on the performance and achievement values, while femininity much more refers to the preference of life quality, fraternal relation, fashion, and care to the weak ones.

Workplace Spirituality. Workplace diversities and individual dissimilarities can shape a variety of dimensions including spirituality dimension. The practice of workplace spirituality must base on the principles of respecting the different, unique, and individual perceptive values (Krishnakumar and Neck, 2002). An organization cannot apply the same principles of spirituality for all employees. Krishnakumar .S.and CP Neck (2002) developed an individualleveled spirituality enrichment model called as 'spiritual freedom model'. In this model, the workplace spirituality enrichment is supported and ensured freely, along with the open expression, intuition, creativity, honesty, authenticity, reliance, and personal fulfillment that are in the positive atmosphere. Milliman et al. (2003) stated that some leading business magazines, such as Bussiness Week and Fortune, have workplace spirituality theme as the cover story. The primary reason as proposed by Chand \& Koul (2012) is that, in the continuous dynamic condition and change happening today, a manager is challenged to create a comfortable workplace environment. Robbins (2005) defined workplace spirituality as follow:

"Workplace spirituality recognizes that people have an inner life that nourishes and is nourished by meaningful work that takes place in the context of community. Organizations that promote a spiritual culture recognize that people have both mind and spirit, seek to find 
the meaning and purpose in their work, and desire to connect with other human being and be part of a community".

Highlighting the hierarchy of workplace spirituality has become one of the focuses of this study. There were three key dimensions of workplace spirituality used (adopted from Milliman et al., 2003), including purpose in one's work or "meaningful work", having a "sense of community", and being in "alignment with the organization's values" and mission. Each of those dimensions represented three levels of workplace spirituality, namely individual, group, and organizational levels. Additionally, according to Wainana et al. (2014), if employees are allowed to bring spirituality attributes to a workplace, it will greatly help in giving motivation. Conversely, if they are not allowed, it will result in various problems such as low morale factor, low productivity, and no commitment to an organization.

Organizational Commitments. A commitment is a term that has wide enough meaning and gets much concern in the context of organization or sociology. Luthans (2001) stated that an organizational commitment is often defined as: (1) a strong willingness to keep being the member of a certain organization, (2) a willingness to conduct all efforts on behalf of the organization, (3) a strong belief and acceptance of the values and goals of organization. In other words, those attitudes reflect the employees' loyalty to their organizations and refer to a continuous process in which the participants of organization express their concern on the organization, their successes, and viabilities. Robbins (2008) defined a commitment to an organization as the employees' feelings to stay in the organization. This feeling is created through the internalization of normative pressure put on an individual before or after he enters an organization. This study examined the organizational commitment by using the theory of Allen and Meyer (1990), covering affective, normative and continuous commitments.

\section{CONCEPTUAL FRAMEWORK}

A conceptual framework is proposed to explain the phenomena of deviance behavior on regional government instance/Institute, which is influenced by ethical climate, national culture, workplace spirituality and organizational commitment. The conceptual framework shows a support to the previous studies' results regarding the relation between the examined variables.

Ethical Climates and Deviant Behaviors. There were some previous studies discussing the relevance between ethical climates and deviant behaviors. Some of those studies showed that organizational ethical climates significantly have influenced employees' ethical behaviors (Deshpande et al., 2000; Fritzche, 2000; Trevino et al., 1998). In another side, Wimbush and Shepard (1994) stated that organizational ethical climates couldn't only be related to employees' ethical behaviors, but also to a variety of behaviors including counterproductive behaviors such as delay, absence, and weak performance. This supports the result of the study done by Bulutler and Oz (2009) stating that ethical climates are related to counterproductive or deviant behaviors such as intimidation actions. The other result of the study on ethical climates and deviant behaviors by Mayer et al. (2010) found that ethical climates have a negative relation to employees' negative behaviors, whereas a study done by Vardi (2001) revealed that there is a significant negative relation between organizational ethical climates and organizational deviant behaviors. Meanwhile, Peterson (2002) discovered some relations between deviance types and ethical climates in an organization, in which organizational production deviance has a negative relation to instrumental ethical climate, the climate of independence, and climate of concern. The deviance on organizational wealth significantly relates to the rules and laws of ethical climates as well as the professionalism of ethical climates. As for the personal deviance, it does not relate to organizational ethical climate but tends to relate to an individual characteristic.

Ethical Climates and Workplace Spirituality. The relation of ethical climates and workplace spirituality has also been examined directly by Golestanipour (2016) in which it was found that ethical climates have a correlation with workplace spirituality. Additionally, Cullen. J.B et al (2003), which is basically discovered that ethical climates positively correlate 
with organizational spirituality, revealed that ethical climates on individual and local levels, namely ethical benevolence and ethical principle, is highly influential in developing organizational spirituality, instead of ethical egoism. Mathew I.Sheep (2006) in his study explained that the two ethical dilemmas relate to workplace spirituality.

Workplace Spirituality and Deviant Behaviors. The placement of workplace spirituality variable as one of the mediation variables between ethical climates and deviant behaviors was based on the results of previous studies stating that ethical climates have a correlation with workplace spirituality and workplace spirituality relates to deviant behaviors. According to Wainana et al. (2014), if employees are allowed to bring spirituality attributes to a workplace, it will greatly help in giving motivation. Conversely, if they are not allowed, it will result in various problems such as low morale factor, low productivity, and no commitment to an organization. Furthermore, Asrun (2012) explained that workplace spirituality influences the deviant behaviors of local government officials. In linear, Rahman et al. (2014) stated that the employees/officials who have high spirituality level will show less workplace deviant behavior.

Workplace Spirituality Mediating Ethical Climates and Deviant Behaviors. The variable of ethical climates can directly influence deviant behaviors or else mediated by other factors such as workplace spirituality. The basis of this premise is the former studies done partially, regarding (1) The Effect of Ethical Climate on Workplace Spirituality, and (2) The Effect of Workplace Spirituality on Deviant Behavior. McGhee and Grant (2008) explained that spirituality and ethics are strongly related. Similarly, the study done by Golestanipour (2016) found that ethical climates positively correlate with organizational spirituality. Moreover, Ahmad \& Omar (2014), Rahim et al. (2014), Asrun et al.(2012) discovered that there is a negative correlation between workplace spirituality and deviant behaviors.

National Cultures and Deviant Behaviors. The impact of national cultures on deviant behaviors has not been much examined empirically. In fact, some literature suggested that cultural factors, including national cultures, seriously have influenced a variety of activities, products, and services resulted by organizations. Dewi Faikhotul (2000) in her study found that national cultures together have an effect on deviant behaviors. However, in partial, it was concluded that the dimension of power distance does not influence deviant behaviors. Additionally, the study by K. Praven et al. (2005) discovered that the culture of Hofstede has a negative impact on the deviant behavior of absenteeism, while Bocher and Beril (1994) stated that the cultural dimensions of Hofstede, namely power distance, individualism, and collectivism, have a relation to discrimination and also non-normative behaviors.

National Cultures and Workplace Spirituality. In addition, to be influenced by ethical climate factor, workplace spirituality is also highly influenced by the factor of national culture. Campesino \& Schwartz (2006) did one of the previous empirical studies on the relation between national cultures and spirituality. Sherafati et al. (2015) and Chaty Driscol and Margareth McKes (2006) Iso revealed the statement saying that national cultures have a strong relation to workplace spirituality. In another side, Monthon Sorakraikitikul and Siengthai (2011) explained that the importance of learning organizational cultures closely relates to the development of workplace spirituality such as inner life, meaningful work, sense of community, and self-work integration. Another study was done by Sherafati et al. (2015) also found that cultures (which according to Denisson include adaptability and respectability) have a significant relation to workplace spirituality, especially to the dimension of meaningful work.

Workplace Spirituality Mediating National Cultures and Deviant Behaviors. Other than ethical climates, national cultures can also influence deviant behaviors. The basis of the premise is the previous studies stating that (1) national cultures influence spirituality, and (2) spirituality influences deviant workplace behaviors. The result of the study done by Campesino \& Schwartz (2006) concluded that the conceptualization of spirituality must be done in the context of natural reality so that it can give a comprehensive explanation regarding the spiritual experiences of different groups. Mc.Ghee \& Grant (2008) clarified that spirituality and ethics are strongly related each other, and Golestanipour (2006) indicated that ethics positively correlate with organizational spirituality. Furthermore, Ahmad \& Omar 
(2014), Rahim et al. (2014) and Asrun (2012) found that there is a negative correlation between workplace spirituality and deviant behaviors.

Ethical Climates and Organizational Commitments. The placement of organizational commitment variable as one of the mediation variables (in addition to workplace spirituality) was also based on the result of the previous studies stating that ethical climates have a strong correlation with organizational commitments (Shafer, 2009; Valentine et al., 2002; Fu, 2014; Borhani et al. 2014) and that organizational commitments strongly relate to deviant behaviors. The result of the study done by Shafer (2009) discovered that there is a negative effect of the ethical climates of egoism and principle on affective commitments, while the relation between the ethical climates of both benevolence and principle has a positive impact. Meanwhile, Fahriba Bohani (2000) stated that there are both positive and negative relations between ethical climates and organizational commitments.

Organizational Commitments and Deviant Behaviors. Organizational commitments also have a correlation with deviant behaviors. Gill et al. (2011) found that not all dimensions of commitment positively relates to deviant behaviors. Affective commitments are known to have a negative relation to deviant behaviors. Dalal (2005) and Spector \& Fox (2002) clarified that employees who have a strong commitment to an organization tend to have relatively few negative attitudes. Furthermore, Gill et al. (2000) stated that affective commitments negatively correlate with deviant behaviors, whereas sustainability commitments have a positive relation to deviant behaviors.

Organization Commitments Mediating Ethical Climates and Deviant Behaviors. The variable, which is able to mediate the relation ethical climates and deviant behaviors, is organizational commitments. That is, ethical climates correlate with organizational commitments, and then organizational commitments are also related to deviant workplace behaviors. The empirical evidence of the relation between ethical climates and organizational commitments is what Borhani et al. (2013) have done. The study was done to the nurses working in the hospital in Iran. The result of the study showed that there is a positive correlation between ethical climates and organizational commitments. The relation between both variables is either symmetrical or reversible. Fu (2014) also examined the relation between organizational commitments and ethical behaviors. Moreover, the result proved that there is a positive relation between both variables. In another side, the results of some studies also discovered that there is a significant correlation between organizational commitments and deviant workplace behaviors. Additionally, Gill et al. (2011) defined that affective commitments are a very strong predictor of deviant workplace behaviors. Thus, organizational commitments can mediate ethical climates and deviant behaviors.

National Cultures and Organizational Commitments. Some studies finding the relation between national cultures and organizational commitments are Gelade et al. (2006), Randall (1993) and Kirkman. B.L, dan DL Shapiro (2001), Hammed \& MdSaaid (2012) . Besides, cultures generally have a relation to employees' work satisfaction and organizational commitments. An appropriate application of cultures will result in work satisfaction and influence employees' commitments to an organization. Some studies focusing on the relation between organizational commitments and deviant behaviors were conducted by Harginder et al. (2009), Dallat (2005), Rego and Pina (2000), and Pawar (2009).

Organizational Commitments Mediating National Cultures and Deviant Behaviors. One of the variables, which can mediate the relation between national cultures and deviant behavior, is organizational commitments. That is, national cultures have a significant correlation with organizational commitments, and organizational commitments henceforth have a correlation with deviant behaviors. Gelade et al. (2006) developed a study on national cultures in relation to the organizational commitments on 49 states in which it turned out that, in general, national cultures have negative impacts on organizational commitments, particularly on affective commitments, because it is much related to personality dimension. In another side, organizational commitment also influences deviant workplace behaviors. Gill et al. (2011) found that affective commitments negatively correlate with deviant behaviors, while ongoing commitments positively and moderately correlate with deviant workplace behaviors. 


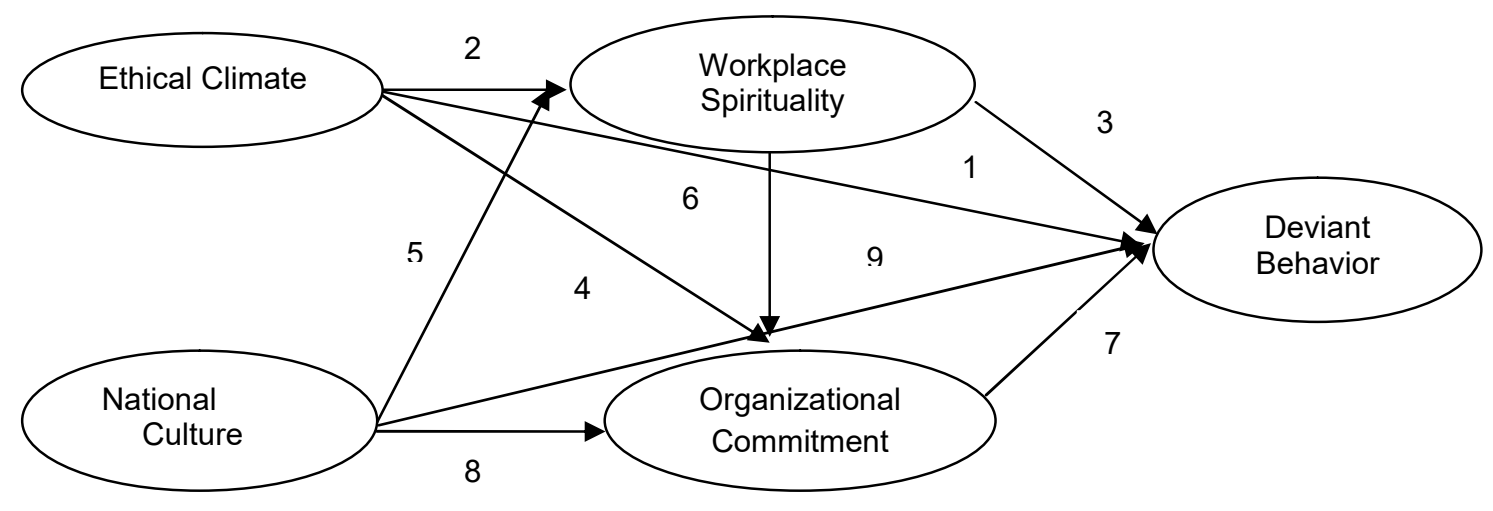

Figure 1 - The Conceptual Framework of the Study

Workplace Spirituality and Organizational Commitments. Jose and Ruth (2015) with the number of samples of 139 people in the US did a study on the relation between workplace spirituality and organizational commitments. In that study, it was found that workplaceindividual spirituality has a relation to affective commitments and innovative behaviors. The other study was also done by Ehsan and Naeem (2010) to some faculties in Pakistan in which it was discovered that spirituality, particularly individual spirituality, has relations to organizational commitments and work satisfaction. Another study was done by Rego and Pina (2008) also found that workplace spirituality has a strong relation to affective commitments but has a weak relation to sustainability commitments. Similarly, Pawar (2009) stated that workplace spirituality correlates with work attitude, work involvement, and commitments.

\section{CONCLUSION}

Based on the theoretical review and the previous studies, it is found that Ethical Climates and National Cultures can directly influence deviant workplace behaviors. However, ethical climates and national cultures, which are the internal factors, will increasingly influence the deviant behaviors, by also including workplace spirituality and organizational commitments. The well-applied ethical values in Regional Apparatus Organization (OPD) will be able to improve the work spirituality and reduce the deviant behaviors of civil servants (PNS).

This study will be more contributive if the relation among ethical climates, national cultures, and workplace spirituality can increase the employees' commitments to the organization. The commitment of Civil State Apparatus $(A S N)$ is very needed to generate employees with a good performance, good behavior, and good work productivity.

Because the focus of this study is on how to examine the important factors influencing deviant behaviors (either directly or indirectly), it is expected that the final result of this study can elicit what should be done to increase the function of appropriate ethical climate application by the organization, also on how to increase the values contained in national cultures. Indeed, it is also very important for the head of the organization to understand that the values of workplace spirituality should also have a space in the organization. Finally, all of those variables can give good impacts on the decreased deviant workplace behaviors.

\section{REFERENCES}

1. Ahmad, A. and Omar, Z. (2014). Reducing deviant behavior through workplace spirituality and job satisfaction. Asian Sosial Science, 10(19):107-112.

2. Appelbaum. S.H, Kyle J.D., and Mathew, L. (2005). The relathionship of Ethical Climate to Deviant Workplace Behavior. Matthieu Corporate Governance, 5:4. 
3. Kirkman, B.I and Shapiro, D.L. (2001) The Impact of Cultural Values on Job Satisfaction and organizational commitment in Self-Managing work tams: The Mediating role of Employee Resistance. Academic of Management Journal.

4. Bruursema, K. (2004). Leadership style and the link with counterproductive work behavior (CWB): An investigation using the job-stress/CWB model. Unpublished Master's Thesis, University of South Florida, USA

5. Bennett, R.J. and Robinson, S.L. (2000). Development of a Measure of Workplace Deviance. Journal of Applied Psychology, 3(85): 349-360.

6. Bollin A and L Heatherly (2001). Predictor of employee deviance: The relationship between bad attitude and bad behavior. Journal of Business and Pshycology

7. Bulutler, F. and Ela, U.O. (2009). The effect of ethical climate on bullying behavior in workplace. Journal of Business Ethics. 86(3): 424-455

8. Borhani, F., Jalali, T., Abbaszadeh, A., and Haghdoost, A. (2014). Nurses' perception of ethical climate and organizational commitment. Nursing Ethics, Vol. 21(3) 278-288

9. Cullen. J.B. et al (2003) The Effect of the Ethical Climates on Organiztional Commitment: a two stud analysis. Journal of Business Ethics, 2(46): 127-14.

10. Chand, P. and Koul, H. (2012). Organizational emotional ownership, workplace spirituality and job satisfaction as moderators of job stress. International Journal of Humanities and Applied Sciences, 1(2): 2012.

11. Dalal, R.S. (2005). A Meta-analysis of the relationship between organizational citizenship behavior and counterproductive work behavior. The Journal of Applied Psychology, 90(6), 1241-1255.

12. Driscoll, C. and McKee, M. (2006). Restoryng a culture of ethical and spiritual values: A role for leader storytelling. Journal of Business Ethics. 73:2003-2017.

13. Fritzche, D.J. (2000). Ethical Climate and Ethical Dimension of Decision making. Journal of Business Ethic, Springer.

14. Fu, W. (2014). The Impact of Emotional Intelligence, Organizational Commitment, and Job Satisfaction on Ethical Behavior of Chinese Employees. J Bus Ethics, 122:137-144.

15. Gill, $H$. et al (2011). Affective and continuance commitment and their relations with deviant workplace behaviors in Korea. Asia Pac J Manag, 28:595-607.

16. Golestanipour, M. (2016). Simple and Multiple Relationship between Ethical Leadership, Transformational Leadership and Ethical Climate and Organizational Spirituality among the employees of Irn National Steel Industrial Group. Review of European Study, 2(8).

17. Hofstede, G. (1983). The cultural relativity of organizational practices and theories. Journal of International Business Studies. Fall.

18. Hofstede, G. (2011). Dimensionalizing Cultures: The Hofstede Model in Context. Online Readings in Psychology and Culture, 2(1).

19. Kirkman B.L. et al (2006). A quarter century of culture's consequances; A reviuew of empirical Research Incorporating Hofstede's Culture Value Framework.

20. Milliman, J., Czaplewski, A.J., and Ferguson, J. (2003). Workplace Spirituality and Employee Work Attitudes: An explonatory empirical assessment. Journal of Organizational Changes Management, 4(16): 426-447.

21. Luthans, F., Baack, D., Taylor, L. (2001). Organizational Commitment: Analysis of antecedents. Human Relation, 4(40): 219-236.

22. Sherafati, M., and R Mohammadi (2015). The study of the effect of organizational culture on organizational spirituality. Europan Online Journal of Natural and Social Science, 1(4).

23. Meyer, J.P., and Allen, M.J. (1990). The Measurement and Antecedents of Affective, Continuance and Normative Commitment to the Organization. Journal of Occupational Psychological Society.

24. McGhee, P. and Gran, P. (2008). Spirituality and the ethical behavior in workplace: Wishful Thinking or Authentic Reality. Electronic Journal of Business Ethics and Organization Studies, 2(13).

25. Mount, M., Ilies, R., Jhonson, E. (2006). Relationship of personality traits and counterproductive work behavior: The mediating effect of job satisfaction. Personal Psychology, 56: 591-622. 
26. Malik, M.E. and Naeem, B. (2010). Role of spirituality in job satisfaction and organizational commitment among faculty of institutes of higher learning in Pakistan. African Journal of Business Management, 5(4): 1236-1244,

27. Sorakraikitikul, M. and Siengthai, S. (2015). Organizational learning culture and workplace spirituality: is knowledge sharing behavior missing link. The Learning Organizational, Vol 21 No 3 pp. 175-192. Emerald Group Published.

28. Nazarian, A., Atkinson, P., and Greaves, L. (2014). The Relationship between National Culture and Organisational Culture: Case of Medium and Large Size Organisations in Iran. The Macrotheme Review, 3(6), Summer 2014

29. Olabimitan, B and Alausa, W.M. (2014). Psychological Factors predicting workplace deviance behavior among nurses in the public health sector in Lagos. Nigerian Journal of Applied Behavioural Sciences, 2 (June) 137-152.

30. Pawar, B.S. (2009). Individual spirituality, workplace spirituality and wrok attitude. An empirical test of direct and interaction effect. Leadership and Organization Development Journal, 8(33): 759-777.

31. Peterson, D. (2002). Deviant Workplace Behavior and the Organizational Ethical Climate. Journal of Business and Psychology, 1(17): 47-61.

32. Randall, L. (1993). Cross - Cultural Research on Organizational Commitment: A review and application of Hofstede's value Survey Module.

33. Rego, A and Cunha, M.P. (2008). Workplace Spirituality and Organizational Commitment. Journal of Organizational Changes Management, 1(21): 53-75.

34. Robinson, S.L. and Bennett, R.J. (1997). A typology of deviant workplace behaviors: A multdimensional. Academy of Management Journal; Apr 1995; 38, 2; ProQuest p. 555

35. Robinson, S.L. and Bennett, R.J. (2000). Development of a Measure of Workplace Deviance. Journal of Applied Psycology, 1(85): 349-60.

36. Schwepker, C.H. (2001). Ethical Climate's Relationship to Job Satisfaction, Organizational Commitment and Turnover Intention in the Sallesforce. Journal of Business Research, 54(1): 39-52.

37. Valentine, S. et al (2006). Employee job response as a function of ethical context and perceived organization Support. Journal of Business Research 59(5): 582-588.

38. Shafer, W.E. (2009). Ethical climate, organizational-professional conflict and organizational commitment. A study of Chinese auditors. Accounting, Auditing \& Accountability Journal, 2009, 7(22): 1087-1110.

39. Krisnakumar, S. and C.P. Neck (2002). The "what, why and "how of spirituality in the workplace. Journal of Managerial Psycology, 3(17): 153-164.

40. Trevino, L.B. Butterfield, K.D., McCabe, D.M. (1998). The Ethical Context in Organization. Influences on Employee Attitude and Behavior. Business Ethic.

41. Vardi, Y. (2001). The Efect of Organizational and Ethical Climate on Misconduct at Work. Journal of Business Ethics, 29: 252-37.

42. Vardi, Y. and Weiner. (1996). Misbehavior in Organizations: A Motivational Framework. Organizational Science, 2(7).

43. Victor, Bart, Jhon.B. Cullen (1988). The Organizational Bases of Ethical Work Climates. Administrative Science Quartely, 1(33): 101.

44. Wainaina, L, Iravo, M., and Waititu, A. (2014). Workplace Spirituality as a Determinant of Organizational Commitment amongst Academic Staff in the Private and Public Universities in Kenya. International Journal of Academic Research in Business and Social Sciences, December 2014, 4(12).

45. Wimbush JC and JM.Shepard (1994). Toward an Understanding of Ethical Climate; Its Relationship ethical behavior and supervisory influence. Journal of Business Ethics. August 1994, 8(13): 637-647.

46. Zribi, H. and Souaï, S. (2013). Deviant Behaviors in Response to Organizational Injustice: Mediator Test for Psychological Contract Breach-The Case of Tunisia. Journal of Business Studies Quarterly 2013, 4(4). 